\title{
Strategi Pemasaran STP (Segmenting, Targeting, Dan Positioning) Pada Produk Kecantikan House Of Beauty Cabang Kota Pematangsiantar
}

\author{
Sri Aderafika Sani ${ }^{1}$, Nuri Aslami ${ }^{2}$ \\ Program Studi Asuransi Syariah, Fakultas Ekonomi Dan Bisnis Islam, \\ Universitas Islam Negeri Sumatra Utara, Indonesia \\ Email : ${ }^{1}$ rafikaade4@gmail.com ,2Nuriaslami@uinsu.ac.id
}

\begin{abstract}
This study aims to explain the marketing strategy of STP (Segmenting, Targeting and Positioning) in marketing the beauty products of House of Beauty Pematangsiantar. The research was taken based on information from the head of the branch manager, customer service, employees and clients of the House of Beauty Pematangsiantar. Thiis research is a qualitative research with descriptive method. From thee research that has been done, the researcheer concludes that the segmenting strategy carried out by the Pematangsiantar House of Beauty is based on geographic and demographic segmentation. The geographic segmentation of the targeted sector is the sector, especially Pematangsiantar City. While the demographic segmentation is students and university students, civil servants, private employees, and mothers in the age range of 17-60 years. For the targeting house of beauty in Pematangsiantar, the main ones are students, women, and private employees. The positioning carried out by the house of beauty is with the concept of Nature Meets Technology which is a combination of active herbal cosmetic ingredients with sophisticated and modern technology beauty equipment. House of Beauty has standardized quality equipment based on medical analysis and consultation, so that it can provide the best results.
\end{abstract}

Keywords : Segmenting, Targeting, Positioning

\begin{abstract}
Abstrak
Penelitian ini memiliki tujuan untuk menjelaskan strategi pemasaran STP (Segmentiing, Targetiing dan Positiioning) dalam memasarkan produk kecantikan House of Beauty Pematangsiantar. Penelitian diambil berdasarkan informasi dari kepala pengelola cabang, customer service, pegawai dan para klien House of Beauty Pematangsiantar. Penelitian ini merupakan penelitian kuallitatif dengan metode deskriptiif. Dari analiisis yang telah dilakukan, peneliiti menyimpulkan bahwa strategi Segmentiing yang dilakukan house of beauty pematangsiantar yaitu berdasarkan pada segmentasi geografiis dan demografiis. Segmentasi geografiis sektor yang dituju yaitu sektor khususnya Kota Pematangsiantar. Sedangkan segmentasi demografisnya yaitu para pelajar dan mahasiswa, pegawai negeri, pegawai swasta, serta ibu-ibu dalam rentang usia 17-60 tahun. Untuk Targeting house of beauty pematangsiantar yang utama yaitu
\end{abstract}


pelajar danmahasiswa, ibu-ibu, serta pegawai swasta. Positioning yang dilakukan house of beauty yaiitu dengan konsep Naturee Meet's Technology yang merupakan perpaduan antara bahanbahan aktif kosmetik herbal dengan peralatan kecantiikan berteknologi canggih dan modern. House of Beauty memiliiki standarisasi peralatan berkualiitas berdasarkan analiisa dan konsultasi mediis,sehingga bisa memberikan hasil terbaiik.

Kata Kunci : Segmenting, Targeting, Positioning

\section{PENDAHULUAN}

Dengan bertambahnya sirkulasi yang pesat, para pemeran usaha semakin tanggap terhadap transmutasi yang terjadi, sehingga melahirkan kompetisi yang ketat terutama didunia pemasaran. Dengan adanya kompetisi yang kuat membuat startegi yang diterapkan pada kurun waktu sebelumnya belum terlaksana. Perusahaan diharuskan meminta dan meluaskan rancangan yang diterapkan agar disesuaikan dengan sirkulasi era ini yang berminat untuk menjaga dan memperluas target pasarnya.

Sekarang ini sudah banyak sekali berdiri kliniik kecantiikan yang memasarkan berbaagai jasa serta perlengkapan kecantiikan, karena didorong oleh semakiin banyaknya kepentingan intensi publik untuk tetap menjaga kecantikan. Ada beberapa kliinik kecantikan terbaiik yang membuka cabang di kota pematangsiantar, salah satunya yaitu dr. Rina Skincare (House of Beauty) serta Klinik Anggun Beauty Center.

Pendiri House of Beauty adalah Dr. Rina Djijo tahun 2001, RD House Beauty menjadikan kliinik kecantiikan yang melahirkan perawaatan sehat pada muka dan badan pelanggan dengan menerapkan teknologii modern canggih saat ini. Dibantu dengan ahli untuk menjadikan harapan pelanggan agar memiiliki kulit muka sehat dan terurus serta tubuh yang sehat dan iindah.

House of beauty senantiiasa memberikan kontribusi terbaiik dengan rancangan Nature Meets Technology yg memiliki campuran antara benih-benih aktiif kosmetiik herbal dengan perlengkapan-perlengkapan kecantiikan yang memakai teknologi modern tiinggi.

Kulit cantik sehat terurus dan tubuh sehat indah merupakan impian bagi semua wanita. House of beauty mempunyai standart perlengkapan bertingkat yang akan diberikan berdasarkan analisa serta pembicaraan dengan ahli medis, sehingga bisa memberikan hasil yang terbaik untuk para pelanggan. Produk dan perlindungan jasa yang ditawarkan house of beauty memakai produk alami, yang dlam pemasrannya mempunyai sanggahan terpisah untuk membudayakan perawatan dan produk nya kepada pelanggan, karena produk yang alami memerlukan waktu yang relatiif cukup lama dibandingkan dengn yang lainnya dalaam memberikan efek yang maksimal. Oleh karena itu house of beauty meluaskan keunggulannya untuk bersaing dengan menerapkan strategi segmentiing, targetiing atau posiitioning perusahaan dengan betul dibenak konsumen.

Target dasar STP adalah memposiisikan suatu merek dibenak konsumen, sehiingga merk tersebut memiliiki dan mempunyai pengaruh kompetiitif yang berkesiinambungan. Salah satu produk akan mempunyai pengaruh kompetiitif jika produk tersebut memiliki manfaat yang pentiing dan khas untuk pelanggan berdasarkan pemikiran (Tjiptono 2007:211). 
Perusahaan mengetahui bahwa tidak semua yang dilakukan dan yang di promosikan bisa menarik semua pelanggan, karena keinginan maupun kemauan konsumen selalu berubahubah. Kondisi iniilah yang dapat memotivasi perusahaan untuk saliing berlomba menjadi yang terbaik dimata semua pelanggan. Berdasarkan maksud diatas, peneliti mendeskripsikan dan menggambarkan terkait segmenting, targeting serta positioning dalam pemasaran house of beauty pematangsiantar.

\section{KAJIAN TEORI}

Straategi pmasaran pada dasarnyaa adalah rencana yang mnyeluruh, terpadu dan mnyatu dibiidang pmasaran, yang memberiikan panduann tentang kegiiatan yang akan dijalankaan untuk memasrkan tujuaan suatu perusahan. Strategii marketiing sangat dibutuhkaan untuk menjuarai kompetisi dan memperkuatkan vol penjualan. Keiinginan dan kemauan konsumen berbedaa antara satu konsumen dengan yanglainnya, oleh karena itu diiperlukan pengelompokkan konsumen yang memiliiki kemauan yang serupa dengan caraa menganaliisa segmentiing, targetiing dan posiitioning (STP).

Dalam bidang marketiing kita memahami STP (Segmentiing, Targetiing, and Positiioning) sebagai strategii pmasaran komoditas ataupun jasaa. Menurut Kotler (2012:292) terdapat 3 komponen dalam rancangan pmasaran yaitu segmentiing, targetiing, dan posiitioning.

1) Segmenting adalah prosess mengelompokkan keseluruhanyang heterogen kekelompokkelompok atau segmensegmen yang memiiliki kesamaan dalam hal kebutuhaan, keiinginan, periilaku, danrespon terhadap programprogram pmasaran spesiifik.

Segmentiing adalah membagi kelompok-kelompok pembeli dari sebuah pasar dengan keiinginan, karakteriistik, dan periilaku yang berbedabeda. (Kotler dan Amstrong 2008:46)

Segmentasii pasar adalah kegiiatan untuk membagii pasar konsumen kekelompokkelompok yang berbeda. Consumen yang mempunyaii cirii siifat yang sama atau hampiir sama masing-masing dari sebuah kelompok tersebut. (Sofjan Assauri : 2015)

2) Targeting merupakaan kegiatan yang menentukan pasar sasaran, yaiitu tiindakan memiilih satu atau lebiih segmen untuk diilayanin.

Mengevaluasi, memiilih, menyeleksii, dan menjangkau konsumen yang akan menjadii sasaaran adalah targetiing. (menurut kotler 2008)

3) Positioning, yaiitu bagaiimana perusahaan menjeelaskan posiisi produk kepada konsumen. Apabedanya produk milik perusahaan dibandiingkan dengan produk pesaiing dan apasaja keunggulannyaa.

Menurut Tjiiptono dan Chandra (2012) Positiioning adalah suatu tiindakan atau langkah-langkah yang diilakukan oleh perusahan dalam upayaa pnawaran niilai dimana konsumen mengertii dan menghargaii apa yang dilakukan suatu perusahan dibandiingkan dengan pesaiingnya di satu segmen Posiivlumetioning adalah menempatkan product untuk kelompok tersebut atau segmentasii, namun berusahaa menanamkan ciitra produk pada benak konsumen pada segmen yang sudah dipiilih. 
Tabel 1. Hubungan STP dengan Strategi Pemasaran

\begin{tabular}{|c|c|c|}
\hline Segmenting & Targeting & Positioning \\
\hline $\begin{array}{l}\text { Mengidentifikasi } \\
\text { variabel segmentasi } \\
\text { dan segmentasi pasar. } \\
\text { Mengembangkan } \\
\text { bentuk segmen yang } \\
\text { menguntungkan }\end{array}$ & $\begin{array}{l}\text { Mengevaluasi daya } \\
\text { tarik masing-masing } \\
\text { segmen. } \\
\text { Memilih segmen- } \\
\text { segmen sasaran. }\end{array}$ & $\begin{array}{l}\text { Mengidentifikasi } \\
\text { konsep positioning } \\
\text { yang mungkin bagi } \\
\text { masing-masing } \\
\text { segmen sasaran. } \\
\text { - Memilih, } \\
\text { mengembangkan } \\
\text { dan } \\
\text { mengkomunikasikan } \\
\text { konsep positioning } \\
\text { yang dipilih }\end{array}$ \\
\hline
\end{tabular}

Sumber : Tjiptono(2012)

\section{METODE PENELITIAN}

Analisis ini menggunakan analisis kualiitatif dengan pendekatan deskriptiif yang bermaksud memaparkan tentang segmentiing, targetiing dan positioniing dalam pemasran yang diilakukan oleh house of beauty pematangsiantar. Penentuan lokasii analisis menggunakan sistem purposiive area. Subjek dalam analisis ini adalah kepala pengelola cabang sebagai koresponden yang betul-betul mengetahui masalah yang diteliti, dan koresponden pelengkapnya adalah customerservice dan pelanggan. Metode penyatuan fakta yaitu memakai sistem wawancara, sistem pemeriksaan dan sistem dokumen.

\section{HASIL PENELITIAN DAN PEMBAHASAN}

Berdasarkan analiisis yang dilakukaan, House Of Beauty merupakan kliinik kecantiikan yang didirikan oleh Dr.RinaDjijo tahun 2001, House of Beauty merupakan kliinik kecantiikan yang memberikan perlindungan yang berguna pada muka dan badan pelanggan dengan menyatukan teknologi modern terkini. Dibantu oleh ahli medis yang siap membantu pelanggan dalam mewujudkan harapan pelanggan untuk mempunyai kuliit wajah sehat dan terurus serta tubuh yang sehat dan indah.

Sudah menjadi tugas dan tanggungjawab House of Beauty untuk senantiasa menyerahkan kontribusi yang baik dengan rancangan Nature Meets Technology yang menjadikan percampuran antara benih-benih aktif kosmetik herbal pakai perlengkapanperlengkapan kecantiikan berteknologi tinggi yang disinergiikan melewati teknologi maju serta harga yang lebih terjangkau.

Selain mempromosikan jasa perawatan kuliit house of beauty juga memberikan produk kosmetiik pribadi menggunakan benih alami yang tenang dan tentram serta sudah memiiliki sertifikat CPKB (Cara Pembuatan Kosmetik yang Baiik) mulai sejak BPOM RI THN 2006. House of Beauty pematangsiantar merupakaan cabang ke4 dari 5 cabang yg beralamat di JLN H.Adam Malik No.20 Timbang Galung, Kec.Siantar Barat,Kota Pematangsiantar,Sumatra Utara. 
Dari hasil analisis yang ada bahwa House of Beauty Pematangsiantar dalam mempromosikan produk dan jasa nya yaitu melalui strategii STP. Hasil persepsi darii analisis mengenai STP adalah sebagai beriikut:

\section{Segmentasi Pasar (Segmenting) yang Dilakukan House of Beauty Pematangsiantar}

Segmentasii pasar yang dilakukaan dengan target agar mendeteksi pasar mana yang berpotensial untuk dijadiikan tujuan pasar sehiingga bisa meniingkatkan perkiraan kunjungaan. Strategii segmentiing yang dilakukan house of beauty pematangsiantar yaitu didasarkan pada segmentasii geografiis dan demografiis. Segmentasi geografiis dalam pemasaran produk dan jasaa yg diitawarkan bukan hanya pada sektor pematangsiantar saja, melaiinkan di wilayah kota bahkan kabupaten simalungun seperti zona yang potensiial dalam mengarahkan pasar target untuk mengizinkan target dan kebutuhan konsumen. Hal ini dibuktiikan dengan semkin canggiihnya teknologii era modern saatini.

House of beauty pematangsiantar mempunyai kesempatan untuk melakukan promosii menggunakan instagraam dan facebok yg mudah diikenal oleh masyaraakat, selaiin itu juga ada websiite yg memberiikan fasilitas untuk memperoleh petunjuk mengenai produk dan treatmentt yg diitawarkan. Segmentasii demografiisnya meliputi, pegawai negeri, pegawai swasta mahasiiswa dan mama-mama muda. Semua itu di pilih karna liingkungan house of beauty pematangsiantar ada diipusat kota, tepatnya di kecamatan siantar barat. Kecamatan siantar barat menjadiikan salahsatu kecamatan di pematangsiantar yang mempunyai tahap kerapatan yang tiinggi karena banyak perkantoran danfasiilitas pembelajaraan serta sangat dekat dengan pusat kota. Umur yg dituju yaitu rentang umur 17-60 tahun karena berhubungan dengan kebutuhaan, kemauan, dan masalah kuliit. House of beauty pematangsiantar ditujukan kepada lingkungan yang berpenghasiilan menengaah dan berpenghasilan mengengaah kebawah.

\section{Targeting yang dilakukan House of Beauty Pematangsiantar}

Strategi yang dilakukan House of Beauty Pematangsiantar dalam memutuskan tujuan pasarannya adalah dengan mengamati ukuraan atau lebarnya segmenn yg telah dipiliih. Segmenn pasar yang dipiliih untuk dijadiikan tujuan pasar adalah mahasiiswa, ibuibu, dan pegawai swasta, karena tujuan standar tersebuut diianggap mempunyai tahap perkembangan penjualan yang tinggii karena hargaa yang ditawarkaan masiih mudah untuk dijangkauu. Mahasiiswa dan ibuibu masa ini tetap mempunyai kemauan dalam merawat badan dan muka nya untuk selalu kelihatan cantiik dipergaulan maupun dikawasan masyarakat.

Perusahaan saat ini banyaak yg memaksa karyawannya untuk memperhatikan penampiilan saat bekerjaa, misalnya penampiilan rambut dan muka. Strategii penetapan target tujuan house of beauty pematangsiantar memperuntukan rancangan penetapan majemuuk (Multiisegment Targetiing Strategy) yaitu perusahaan mematuhi peraturan pemasaraan majemuuk, dimanaa perusahaan membuat sejumlah macam perlindungan dan komoditas langka dalam membolehkan keinginan semua pelanggan.

\section{Positioning yang Dilakukan House of Beauty Pematangsiantar}

Positioniing adalah peraturan yang dilakukaan perusahaan dalam merencanakan ciitra komoditas untuk mendapatkaan periingkat yang baiik dibenak pelanggan. House of 
Beauty Pematangsiantar dalam melakaukan positioniing menggunakan sejumlah penyebab yaitu:

\section{a) Atribut Merek}

Merek House of Beauty Pematangsiantar udah dikenal diberbagai kalangan dari tahun 2001, House of Beauty udah mempunyai banyak pelanggan yg tersebar dibeberapa kota, salah satunya kota Pematangsiantar.

Atriibut merek ditanamkaan untuk pelanggan melaluii semboyan dan ciitra nerek yg diterapkan dalam melayani pelanggan. House of Beauty pematangsiantar selalu menggunakan salam seperti petunjuk identitas house of beauty yang berbunyii "salam kuliit sehat". Salam tersebut berkeiinginan untuk menyerahkan penghormataan untuk pelanggan, bukan hanya itu saja, salam juga termasuk memaparkan tentang karakter identitas bahwa kliinik kecantiikan tersebut mempromosikan perawatandan produk yg bahan utamanyaa menggunakan benih alamii yg sehat untuk kuliit. Selain salam, dalam memberiikan kontribusi House of Beauty pematangsiantar mengarahkan pada jasa kualitas yang bersumber darii pusat. Kebiijakan kualitas diilakukan dengan memperkuatkan kualiitas bahan yang dimiiliki dan kualitas pekerja untuk memuaaskan penggaan. Ciitra merek yg ditanamkan kepada pelanggan yaiitu dengan mengatakan keuntungan darii penggunaan produk dan perlindungan darii House of Beauty. Untuk membuat hasiil yang maksiimal. Hasiil yg diperoleh tiidak datang secaraa langsung tetapii adanya tahapan karena bahan bersumber darii benih alamii yg berkehendak tidak mempunyai efeek sampiing. Bahan alamii akan terasaa manfaatnya apabilaa diigunakan secara rutiin dan tersusun untuk memelihara kondiisi kuliit yg sehat.

\section{b) Harga dan Kualitas}

Salah satu kelebihan House of Beauty pematangsiantar yaiitu harga lebiih terjangkau dibandiing dengan para pesaingnyaa, karna benih yang digunakaan menggunakan benih alamii. Bahan alamii termasuk dalam perolehannyaa mudah didapatkaan diindonesia dan harganya relatiif murah. Meskiipun harganya murah House of Beauty pematangsiantar menjaga tahap kenyamanan dan kesehataan kuliit dengan memberikan asuransii musibah tubuh kepada para pelanggannya. Harga yg diitawarkan sudah dalaam rentetan perawataan, perlindungan yang biisa diikatakan murah yaiitu perawatanorganiik dengan harga Rp.75,000 sampai HTD ataupun tiindakan dokter dengan harga rp.350.000, semuaa itu udah terhitung konsultasii dokter, perawatan sepertii cleansiing, peeliing, message dan tiindakan dokter lainnya. Semua harga menyelaraskan dengan keinginan pelanggan dan tiidak adanya tekanan untuk melakukaan transaksii perawatanmaupun pembelian produk.

\section{c) Pesaing}

Banyaknyaa kliinik kecantiikan yang berada diPematangsiantar mengakiibatkan persaiingan yang kuat, untuk dapat bersaiing dengan para pesaiingnya, pelaayanan merupakaan hal utama yg diperhatiikan dalam menghadapii pelanggan. Pelayanan yang diberiikan perusahan berbeda dengan yang lainnya karena produk yg diigunakan merupakan produk indiividu. House of beauty pematangsiantar berusaha pedulii terhadap permasalahaan, produk, serta perawataan yang diinginkaan oleh pelanggan. Pelanggan tidak dipaksaa untuk menggunaakan produk, tetapi konsumen disarankan agar konsultasii dengan dokterr dengan permasalahaan yang dialamii. Rancangan layanan yang diberiikan mengutamakan tata cara berbiicara yang baiik, sopansantun dan 
menariik konsumen untuk datang kembalii dengan menginformasiikan promopromo yang berlaku.

Upaya ini telah memenuhii Internasional standar yg mengatur tentang system mutu manajemenn. Penerapan standarr ini merupakan salahsatu kemajuan dan niilai tambah sendiiri untuk pelanggan memiilih kliinik kecantiikan. Prusahaan slalu menampung konsumen kriitik dan saran untuk terciiptanya kenyamanan dan loyaliitas konsumen. Selaiin itu loyaliitas konsumen diilakukan dengan selalu mengecek danmengevaluasi daya trafiik perbulan, jika trafiik mengalami penurunan House of Beauty Pematangsiantar langsung mengadaakan promoo untuk menstabiilkan jumlah kunjuungan.

\section{PEMBAHASAN}

Berdasarkan hasiil peneliitian yang diijelaskan, strategii pemasaran yang diilakukan House of Beauty Pematangsiantar adalah strategi STP(Segmentiing, Targetiing, Positioniing) yg bertujuan untuk memposiisikan merek dibenak konsumen, sehiingga merek tersebut memiiliki keunggulan yang kompetiitif yang berskesiinambungan. Sebuahproduk memiIliki keunggulan kompetiitif jika produk tersebut menawarkan atriibutatribut yang berniilai pentiing dipelanggan menurut (Tjiptono 2007:211). House of Beauty merupakan kliinik kecantiikan yang menghadiirkan perawatan yang efektiif pada muka dan badan anda dengan memadukan teknologii terkiini. Dibantu oleh para ahli yang siap membantu dalam mewujudkann impiian anda untuk memiliiki kuliit wajah sehat dan terurus serta badan yg sehatdan iindah.

Untuk meniingkatkan jumlah kunjungan House of Beauty Pematangsiantar melakukan segmentasii pasar berdasarkaan kebutuuhan serta keingiinan konsumen. Proses segmenntasii pasar diilakukan melaluii promosii baik online maupun offliine. Secara onliine yaitu memanfaatkan mediasosiial seperti Instagraam, WhatsAapp, facebok untuk diikenal wiilayah sasaran. Secara offliine dilakukan dengan penyebaran brosur serta melakukan hubungaan masyarakaat sepertii pengadaan Inclasss diibu PKK \& Dharmawaniita, mengisi semiinar tentang kesehataan kuliit dan muka dikampus negerii maupun swastaa dan membuka openstand. Kegiatan tersebut untuk mengetahui kebutuhan, sikap periilaku konsumen dalam merspon pembeliian dan produk yg diitawarkan.

Kegiiatan tersebut diilakukan sesuaii teorii yang dikemukakan Zeithmall dan Biitner (dalam Lupiiyoadi dan Hamdaani 2006:5) bahwa dalam pemasaran jasa kegiiatan pmasaran perlu diilakukan, dari pmasaran yang diilakukan perusahan akan mengetahuii respoon konsumen sehiingga memudahkan perusahaan dalam mengembaangkan pasar saasaran yang akan ditujuu.

Target pasar House of Beauty Pematangsiantar yang utamaa adalah mahasiiswa, ibuibu dan pegawai swastaa. Pemiliihan target utama disesuaiikan dengan lokasii yg bedekatan dengan liingkungan kampus dan pusat kota. Target utama tersebut diianggap memiliiki tiingkat penjualan yang tiinggi karena selaiin lokasii yang mudah diijangkau, harga yg diitawarkan masiih mudah untuk diijangkau mahasiiswa, ibuibu dan pegawai swastaa. 
Sesuai teorii dari Clanncy dan Shuulman (Kasalii, 2005:375) yg menyataakan bahwaa kriiteria memiliih pasar sasaran yg optiimal yaitu responsiif dan juga potensii penjualan yang cukup luas. Dalam potensii penjualan yang cukupluas, perusahaaan mlakukan strategii penetapan sasaran yang majemuk, dimana House of Beauty Pematangsiantar memandang konsumen sebagaii sebuah pasar yg besar. Sehiingga menciiptakan beberapaa jeniis perawatan jasa\&produk yang berbedaa sehingga dapat memenuhii semua kebutuhan dan permasalahan konsumen secaraa luas.

House of Beauty Pematangsiantar menempatkaan produknyaa diimata konsumen dengan menciiptakan ciipta merek atau ciitra perusahaan untuk menempati posiisi persaiingan yang baik. Ciitra merek tersebut sesuai dengan pendapat Rangkutii (2011:3) bahwa posiitioning adalah kegiiatan menciiptakan ciitra produk atau jasa sebaiik mungkin sehiingga mampu menempati posiisi persaiingan yang baiik dan berbedaa dalam pelanggan sasaranyaa. Ciitra merek yang ditanamkan dikonsumen yaitu dengan memberiitahukan kepadaa konsumen mengenaii manfaat perawatan dan penggunaan produk. Adapun manfaat yang diperoleh yaiitu perawatan jasa dan produk yangditawarkan mengunakan bahan alamii tentunya mana bagi kuliit, menyehatkan dan hasiil yang diberikan tidak muncul scara langsung tetapi melalui taahapan yangrelatif cukup lama.

Zeithmall dan Biitner (dalam Lupiyyoadi\&Hamdaani 2006:5) menjelskan bahwa jasa merupakan kegiiatan ekonomi yg hasiilnya tiidak hanya produk fisiik melaiinkan juga memberikan niilai tambah (miisalnya kenyaamanan, kesehaatan konsumen, keseenangan, hiiburan). Selain menetapkan ciitra merek, untuk mencipitakan kesan yang baik dimata konsumen, yaiitu perusahaan mengutamakan dalam segii kualitas dan pelayanan. Kualiitas dan pelayanan yang diilakukan berpacu pada SOP yang ditetapkan perusahaan dan berpacu pada kebiijakan mutu. Pelayanan yang diberikan kepada konsumen, House of Beauty Pematangsiantar selalu pedulii dengan konsumen yang daatang, peduli disiini dalam artian pedulii mengenai masalah yang dihadapi dan memberikan solusi terbaiik tentang permasalahan yang diialami dengan penggunaan perawatan dan produk yang sudah disediiakan. Konsep layanan yangdiberikan mengedepankan etiika berbiicara, sopansantun, dan tingkah laku yang baik, hal iitu sudah ditetpkan pada SOP.

House of Beauty Pematangsiantar rutiin melakukan komuniikasi dengan para konsumen melaluii mediasosial seperti WhatssApp dan telepon untuk mengiiatkan kedatangannya kembalii didua minggu sekalii dan memberiitahukan promopromo yang sedangberlaku. Kegiiatan yang diilakukan sesuai teorii Zeithmall dan Battner (dalam Lupiyyoadi dan Hamdanii 2006:5) yaiitu tentang pemasaran Interaktiif. House of Beauty Pematangsiantar melakukan interaksii yang baiik antara pegawaidengan pelanggan. Pegawai yang loyal akan memiliiki motiivasi tiinggi untuk memberiikan pelayanan yang terbaiik kepada pelanggan dan menjadiikan pelanggan tetap membina hubungan baiik dengancara menjadiikan piliihan perawatan digerai House of Beauty Pematangsiantar.

\section{PENUTUP}

Berdasarkan hasiil penelitiian yang dilakukaan, disimpulkan bahwa strategi segmentiing yang dilakukan House of Beauty Pematangsiantar yaituu didasarkan pada segmentasii geografiis dan demografiis. Segmentasii geografiis yaitu dalam 
pemasaranya menyebar khususnyaa diwilayah kota pematangsiantar dan kabupaten simalungun. Segmentasii demografiisnya meliiputi: pegawai negeri, pegawai swasta, mahasiiswa, ibuibu, dengan rentang usia 17-60 tahun. Targetiing pasar yang utama yaituu mahasiiswa, ibuibu muda dan pegawai swasta. Strategii penetaapan sasran menggunaakan strategii penetapaan sasaran majemukkarena House of Beauty Pematangsiantar mengangap konsumen sebagaii pasar yg besar sehiingga menciiptakan berbagaiI jeniis perawatan danproduk yg dapat memenuhii kebutuhan konsumen secaraa luas. Positioniing yang dilakukan yaiitu dengan menempatkan ciitra merek dan slogan dibenak konsumen. Berdasarkan hasiil peneliitian, maka peneliiti menyarankan sebaiiknya House of Beauty Pematangsiantar meniingkatkan danmemfokuskan segmentasii pasar untuk kaalangan atas dan melakukan inovasii terhadap komoditas danperawatan sehiingga pelangan semakiin tertariik.

\section{DAFTAR RUJUKAN}

Kasali, R. 2005. Membidik Pasar Indonesia: Segmentasi, Targeting, dan Positioning. Cetakan Ketujuh. Jakarta: PT Gramedia Pustaka Utama.

Lupiyoadi, R., \& Hamdani, A. (2006). Manajemen pemasaran jasa.

Rangkuti, F. (2011). Dongkrak Penjualan melalui marketing strategy \& competitive positioning. Jakarta: PT Gramedia Pustaka Utama.

Kotler, P., \& Armstrong, G. (2008). Prinsip-prinsip pemasaran jilid 1 edisi 12. Jakarta: Erlangga.

Rismawati, F. F., Wahyuni, S., \& Widodo, J. (2019). Strategi Pemasaran STP (Segmenting, Targeting, Positioning) Larissa Aesthetic Center Cabang Jember. Jurnal Pendidikan Ekonomi: Jurnal Ilmiah Ilmu Pendidikan, Ilmu Ekonomi Dan Ilmu Sosial, 13(2), 68-72. http://repository.unej.ac.id/handle/123456789/100137

Rismawati, F. Strategi Pemasaran Stp (Segmenting, Targeting, Positioning) Pada Larissa Aesthetic Center Cabang Jember (Doctoral dissertation, Fakultas Keguruan Dan Ilmu Pendidikan Universitas Jember) https://doi.org/10.19184/jpe.v13i2.10793

Tjiptono, F. (2008). Strategi Pemasaran Edisi 3. Yogyakarta: Andi.

Tjiptono Dan Chandra .2012. Market Targeting. Erlangga: Jakarta

Tjiptono, F.,G. Chandra dan D. Adriana. 2007. Pemasaran Strategik: Yogyakarta: Andi

Assauri, S. (2004). Manajemen Pemasaran: dasar, konsep dan strategi. PT. Grafindo Persada. Jakarta.

https://rdbeauty.id/about (Diakses 30 November 2021, Pukul 14.12 WIB) 